\title{
THỰC TRANG NHU CẦU ĐÀO TẠO NÂNG CAO TRÌNH Độ ĐộI NGŨ ĐIỀU DƯỠNG GÂY MÊ HỒI SỨC TẠI CÁC TRUNG TÂM Y TÊ HUYÊ̂N THUộC TỈNH HẢI DƯƠNG NĂM 2019
}

\section{TÓM TẮT}

Mục tiêu: Khảo sát thực trang nhu câu đào tao nâng cao trình độ đội ngũ điều dưỡng Gây mê hồi sức tại các trung tâm y tế huyện thuộc tỉnh Hải Dương năm 2019. Phương pháp: mô tả cắt ngang có phân tích trên 30 đối tượng làm công việc ĐD GMHS tại 11 TTYTH thuộc tỉnh Hải Dương năm 2019. Kết quả nhu câu đào tạo: đào tạo $\mathrm{DH}$ hệ VLVH $(70 \%)$; đào tạo kiểm soát nhiễm khuẩn phòng mổ $(50 \%)$; đào tạo các lĩnh vực: quản lý đau (40\%), một số kỹ thuật GMHS chuyên sâu (36,7\%), cập nhật một số thuốc mê mới $(36,7 \%)$; sử dụng: máy gây mê $(66,7 \%)$, máy thở $(56,7 \%)$, máy sốc tim $(56,7 \%)$. Kết luận: ĐD GMHS tại TTYTH tỉnh Hải Dương có nhu câuu đào tạo các lĩnh vực Quản lý đau sau $\mathrm{PT}$, một số chăm sóc và kỹ thuật chuyên sâu trong gây mê, cập nhật một số thuốc mê mới, sử dụng máy mê, máy thở, máy sốc tim và công tác kiểm soát nhiểm khuẩn phòng mô.

Tư khóa: điều dưỡng, gây mê hồi sức, trung tâm y tế huyện, kiến thức, đào tạo, trình độ.

\section{SUMMARY \\ CURRENT SITUATION OF TRAINING NEEDS \\ ANESTHESIA NURSING AT DISTRICT HEALTH CENTERS IN HAI DUONG PROVINCE IN 2019}

Background: Survey current situation of training needs anesthesia nursing at district health centers in Hai duong province in 2019. Methods: Crosssectional descriptive studies on 30 people who doing anesthesia nursing jobs. The study was conducted on 11 district health centers in Hai duong province. Results: training bachelor anesthesia nursing (70\%); training operating room infection control (50\%); training pain management $(40 \%)$; training some intensive anesthesia techniques (36.7\%), updated some new anesthetics (36.7\%); training using: anesthesia machine $(66.7 \%)$, ventilator (56.7\%), cardiogenic shock machine (56.7\%). Conclusion: anesthesia nursing at district health centers in Hai duong province have training needs of operating room infection control, pain management, some intensive anesthesia techniques, updated some new anesthetics, using anesthesia machine, ventilator machine, cardiogenic shock machine.

\footnotetext{
${ }^{1}$ Trường đại học Kỹ thuật Y tế Hải Dương,

${ }^{2}$ Trường đại học Kỹ thuật Y tế Hải Dương. Chịu trách nhiệm chính: Nguyễn Thị Minh Thu Email: nguyenthiminhthuktythd@gmail.com Ngày nhận bài: 25.10.2021

Ngày phản biện khoa học: 17.12.2021

Ngày duyệt bài: 27.12.2021
}

Nguyễn Thị Minh Thu' ${ }^{1}$ Vũ Thị Hân ${ }^{2}$

Key words: nursing, anesthesia, district health center, knowledge, training...

\section{I. ĐĂT VẤN ĐỀ}

Gây mê hồi sức (GMHS) là một chuyên ngành sâu, riêng biệt, có nhiệm vụ chống đau và đảm bảo an toàn cho bệnh nhân trong suốt giai đoạn phẫu thuật và hồi tỉnh... đòi hỏi đội ngũ làm GMHS bao gồm bác sĩ và điêuu dưỡng Gây mê hồi sức phải có nên tảng kiến thức vững chắc, kỹ năng chuyên nghiệp, thái độ thấu đáo khi làm việc. Theo điều tra của Vũ Đình Chính năm 2005 tại 28 tỉnh phía Bắc về thực trạng đội ngũ ĐD/KTV cho thấy tỉ lệ kỹ thuật viên (KTV) GMHS không được đào tạo đúng chuyên ngành là $31,2 \%$; thiếu kiến thức là 23,4\% [1]. Đây là một thách thức lớn với cơ sở y tế nói chung, đặc biệt là các cơ sở y tế tuyến đâu, trung tâm y tế huyện (TTYTH), nơi bị hạn chế đâu tư nguôn nhân lực và cơ sở vật chất trang thiết bị. Trường ĐH Kỹ thuật Y tế Hải Dương là cơ sở đào tạo ĐD /KTV GMHS có kinh nghiệm lâu năm, chương trình đào tạo có sự thay đổi, cập nhật nhiêu lần theo cấp độ học và xu thế xã hội. Tìm hiểu nhu câu đào tạo, từ đó thay đổi chương trình đào tạo cho phù hợp, giúp nâng cao kiến thức, bổ sung kỹ năng cho đội ngũ ĐD GMHS là một trong những mục tiêu hướng tới của chúng tôi trong đào tạo toàn diện. Do vậy, chúng tôi thực hiện nghiên cứu này với mong muốn tìm hiểu thực trạng nhu câu đào tạo nâng cao trình độ của đội ngũ điêuu dưỡng Gây mê hồi sức tại các trung tâm y tế huyện thuộc tỉnh Hải Dương năm 2019.

\section{II. ĐỐI TƯợNG VÀ PHƯƠNG PHÁP NGHIÊN CỨU}

2.1. Đối tượng nghiên cứu. Nhân viên làm công việc ĐD GMHS: ĐD GMHS các trình độ đại học (ĐH), cao đẳng (CĐ), trung cấp (KTV), ĐD có chứng chỉ ĐD GMHS; ĐD có giấy chứng nhận ĐD GMHS; ĐD làm công việc ĐD GMHS chưa có văn bằng/chứng chỉ/chứng nhận ĐD GMHS.

\subsection{Phương pháp nghiên cứu}

- Thiết kế nghiên cứu: mô tả cắt ngang có phân tích

- Địa điểm: bao gồm 11 TTYTH: Cẩm Giàng, Bình Giang, Nam Sách, Chí Linh, Kinh Môn, Thanh Hà, Gia Lộc, Thanh Miện, Tứ Kỳ, Ninh Giang, Kim Thành. 
- Thời gian: từ tháng 04/2019 - 04/2020

- Cõ̃ mầu: mẫu toàn bộ, bao gồm: 30 NV làm công việc ĐD GMHS

\subsection{Quy trình thu thâp thông tin}

- Thu thâp số liệu khảo sát

+ Bước 1: Chọn các địa điểm NC: các TTYTH tỉnh Hải Dương

+ Bước 2: Lập danh sách các đối tượng nghiên cứu.

+ Bước 3: Thu thập thông tin. Sau khi thử nghiệm và hiệu chỉnh đầy đủ phiếu điều tra, nhóm đánh giá trực tiếp liên hệ và thu thâp số liệu tại đơn vị được chọn vào NC đánh giá. Tại mỗi đơn vị, quy trình thu thập số liệu được đảm bảo đồng nhất và khách quan. Phiếu được làm sạch trong ngày bởi nhóm đánh giá.

- Thu thập số liệu thứ cấp: Hệ thống các văn

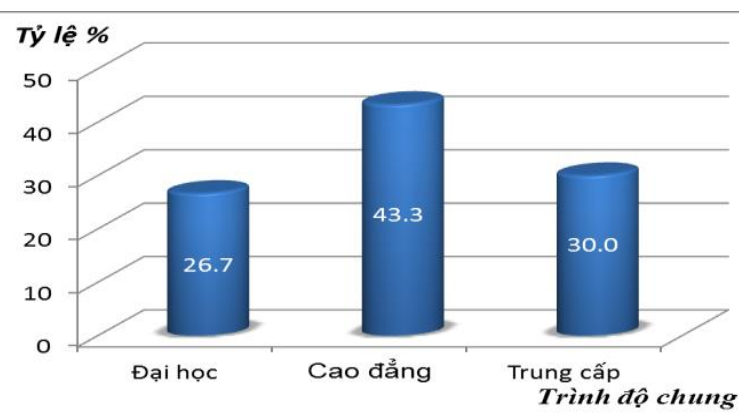

bản, báo cáo, tài liệu thứ cấp có liên quan tới nội dung nghiên cứu.

2.4. Các biến số nghiên cứu (phụ lục)

2.5. Phương pháp thống kê y học: sử dụng phần mềm SPSS 22.0.

\section{KẾT QUẢ NGHIÊN CỨU}

\subsection{Một số đặc điểm chung}

- Tuổi: tuổi trung bình của ĐD GMHS là: $37,23 \pm 9,61$, trẻ nhất 24 tuổi, già nhất 59 tuổi. Độ tuổi làm việc tập chung cao nhất trong nhóm tuổi 25-39 (66,7\%).

- Giới tính: chủ yễu là giới tính nữ (70\%)

\subsection{Trình độ chuyên môn}

\section{-Kiến thức:}

+/ Trình độ chung cao nhất và trình độ chuyên môn GMHS cao nhất:

\section{Biểu đồ 3.1. Phân bố trinh độ chung và trình độ ĐD GMHS cao nhất}

NX: Trình độ GMHS cao nhất là cao đẳng $(46,7 \%), 40 \%$ là trung cấp và $13,3 \%$ ĐD GMHS chỉ có chứng chỉ phụ mê. Số ĐD GMHS học đại học khác là 26,7\%.

+/ Nơi đào tạo: 83,3\% ĐD GMHS được đào tạo chuyên môn tại trường ĐH KTYTHD.

-Một số kỹ năng, thái độ nghề nghiệp:

Bảng 3.1. Phân bố kỹ năng, thái độ nghề nghiệp của ĐD GMHS

\begin{tabular}{|c|c|c|c|c|c|}
\hline TT & Tiêu chí & $\begin{array}{c}\text { Tốt } \\
(n, \%)\end{array}$ & $\begin{array}{l}\text { Trung bình } \\
(\mathrm{n}, \%)\end{array}$ & $\begin{array}{c}\text { Yếu } \\
(n, \%)\end{array}$ & $\begin{array}{c}\text { Tống } \\
(\mathrm{n}, \%)\end{array}$ \\
\hline \multicolumn{6}{|c|}{ Kर̃ năng } \\
\hline 1 & Kỹ năng thực hành chuyên môn & $12(40 \%)$ & $16(53,3 \%)$ & $2(6,7 \%)$ & $30(100 \%)$ \\
\hline 2 & $\begin{array}{c}\text { Kỹ năng quản lý công việc, quản lý } \\
\text { trang thiết bi }\end{array}$ & $\begin{array}{c}16 \\
(53,3 \%)\end{array}$ & $\begin{array}{c}14 \\
(46,7 \%)\end{array}$ & $\begin{array}{c}0 \\
(0 \%)\end{array}$ & $\begin{array}{c}30 \\
(100 \%)\end{array}$ \\
\hline 3 & $\begin{array}{l}\text { Kỹ năng làm việc nhóm (tương tác } \\
\text { với đồng nghiệp) }\end{array}$ & $\begin{array}{c}21 \\
(70 \%)\end{array}$ & $\begin{array}{c}9 \\
(30 \%)\end{array}$ & $\begin{array}{c}0 \\
(0 \%)\end{array}$ & $\begin{array}{c}30 \\
(100 \%)\end{array}$ \\
\hline 4 & $\begin{array}{c}\text { Kỹ năng giao tiếp với BN, người nhà } \\
\text { BN, đồng nghiệp }\end{array}$ & $\begin{array}{c}26 \\
(86,7 \%)\end{array}$ & $\begin{array}{c}4 \\
(13,3 \%)\end{array}$ & $\begin{array}{c}0 \\
(0 \%) \\
\end{array}$ & $\begin{array}{c}30 \\
(100 \%)\end{array}$ \\
\hline \multicolumn{6}{|c|}{ Thái độ } \\
\hline 5 & $\begin{array}{l}\text { Mức độ tuân thủ các quy định trong } \\
\text { luật khám chữa bệnh }\end{array}$ & $\begin{array}{c}24 \\
(80 \%)\end{array}$ & $\begin{array}{c}6 \\
(20 \%)\end{array}$ & $\begin{array}{c}0 \\
(0 \%)\end{array}$ & $\begin{array}{c}30 \\
(100 \%)\end{array}$ \\
\hline 6 & $\begin{array}{c}\text { Khả năng tự học, tự cập nhật kiến } \\
\text { thức nâng cao trình độ }\end{array}$ & $\begin{array}{c}13 \\
(43,4 \%)\end{array}$ & $\begin{array}{c}16 \\
(53,3 \%)\end{array}$ & $\begin{array}{c}1 \\
(3,3 \%)\end{array}$ & $\begin{array}{c}30 \\
(100 \%)\end{array}$ \\
\hline
\end{tabular}

NX: ĐD GMHS tự đánh giá tốt ở các kỹ năng giao tiếp $(86,7 \%)$, kỹ் năng làm việc nhóm $(70 \%)$. Yếu ở kỹ năng thực hành chuyên môn gặp 6,7\%.

ĐD GMHS tự đánh giá tốt ở thái độ tuân thủ các quy định khám chữa bệnh $(80 \%)$; khả năng tự học: tốt $43,4 \%$; trung bình $53,3 \%$ và yếu $3,3 \%$.

3.3. Nhu câu đào tạo nâng cao trình độ 3.3.1. Đào tạo chuyên môn

a/ Hình thức, cơ sở, thời gian, địa điểm đào tạo

Bảng 3.2. Mong muốn của ĐD GMHS về 
hinh thức và quy mô đào tạo

\begin{tabular}{|c|c|c|}
\hline Nội dung & $\begin{array}{c}\text { Số } \\
\text { lương } \\
\text { (n) }\end{array}$ & $\begin{array}{c}\text { Phân } \\
\text { trăm } \\
(\%)\end{array}$ \\
\hline \multicolumn{3}{|c|}{ Hình thức mong muốn được đào tạo } \\
\hline $\begin{array}{l}\text { Hệ VLVH cấp bằng } \\
\text { Đại học ĐD GMHS }\end{array}$ & 21 & 70,0 \\
\hline $\begin{array}{l}\text { Hệ VLVH cấp bằng } \\
\text { Cao đằng ĐD GMHS }\end{array}$ & 2 & 6,7 \\
\hline Khác & 7 & 23,3 \\
\hline \multicolumn{3}{|c|}{ Cơ sở mong muốn được đào tạo } \\
\hline Trường Đại học Y dược Hải Phòng & 1 & 3,3 \\
\hline $\begin{array}{c}\text { Trường Đại học Kỹ thuật Y tế } \\
\text { Hải Dương }\end{array}$ & 23 & 76,7 \\
\hline Khác & 6 & 20,0 \\
\hline \multicolumn{3}{|c|}{ Địa điếm mong muốn đào tạo } \\
\hline Tại cơ sở đào tạo & 15 & 50,0 \\
\hline Tại chố (BV làm việc) & 15 & 50,0 \\
\hline Khác & 0 & 0,0 \\
\hline \multicolumn{3}{|l|}{ Thời gian học tập phù hợp } \\
\hline Những ngày cuối tuân & 28 & 93,3 \\
\hline Những ngày trong tuân & 2 & 6,7 \\
\hline Khác & 0 & 0,0 \\
\hline Tổng & 30 & 100,0 \\
\hline
\end{tabular}

NX: Tỉ lệ ĐD GMHS mong muốn học hệ VLVH cấp bằng đại học là $70 \%$; mong muốn được đào tạo tại trường đại học Kỹ thuật Y tế Hải dương là 76,7\%; mong muốn thời gian học vào cuối tuần là $93,3 \%$.

b/ Nội dung mong muốn đào tạo -Các học phần mong muốn đào tạo:

NX: Tỉ lệ ĐD GMHS mong muốn đào tạo vể phụ mê phụ tê là $66,7 \%$; mong muốn đào tạo về kiểm soát nhiếm khuẩn phòng mổ là $50 \%$.

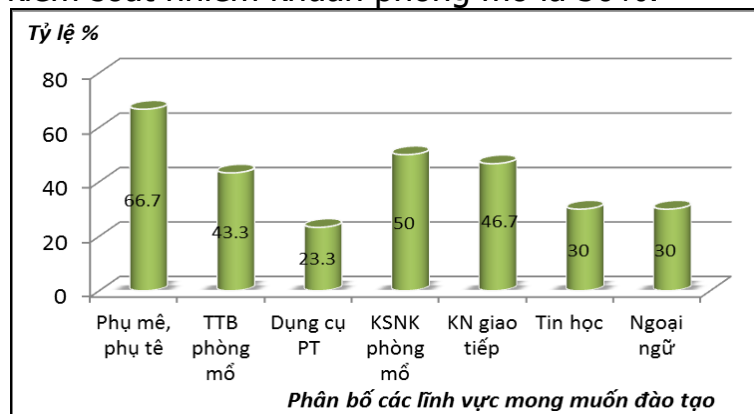

Biểu đồ 3.2.Phân bố các lĩnh vực mong muốn đào tao

- Nội dung mong muốn đào tạo trong lĩnh vực phương tiện hỗ trợ gây mê:

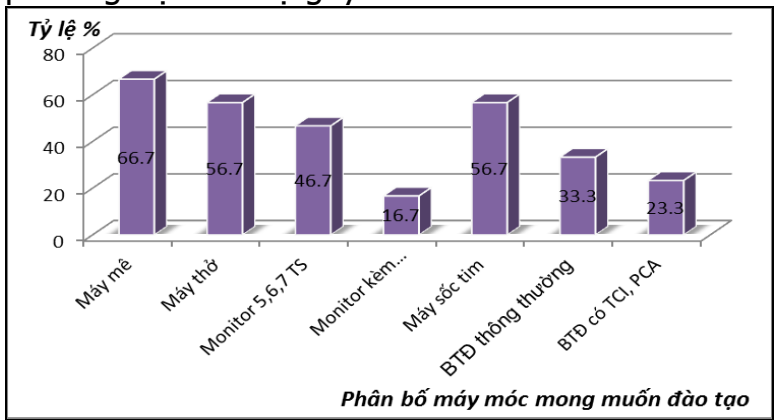

Biểu đồ 3.3. Phân bố nội dung phương tiện hỗ trợ gây mê mong muốn đào tạo

$\mathrm{NX}$ : $66,7 \%$ ĐD GMHS mong muốn được đào tạo máy gây mê; $56,7 \%$ ĐD GMHS mong muốn được đào tạo máy thở và máy shock tim.

-Nội dung mong muốn đào tạo trong lĩnh vực phụ mê $(n=30)$ :

Bảng 3.3.Nội dung mong muốn đào tạo về kiến thức phụ mê

\begin{tabular}{|c|c|c|}
\hline Kiến thức phụ mê & Số lượng $(n, \%)$ & Nội dung \\
\hline $\begin{array}{l}\text { Thuốc dùng trong } \\
\text { GMHS }\end{array}$ & $11(36,7 \%)$ & $\begin{array}{l}\text { - Etomidat - Vecuronium - Naloxone } \\
\text { - Nicacdipin - Lipofundin } \\
\text { - Các thuốc mới hiện nay }\end{array}$ \\
\hline $\begin{array}{c}\text { Kỹ thuật, phương pháp } \\
\text { gây mê }\end{array}$ & $11(36,7 \%)$ & $\begin{array}{l}\text { - Đă̆t NKQ ngược dòng } \\
\text { - Xử trí đặt NKQ khó } \\
\text { - Gây mê hô hấp các lưu lượng } \\
\text { - Gây tê ĐRTK cổ nông, ĐRTK cánh tay } \\
\text { - Xử trí ngộ độc thuốc tê }\end{array}$ \\
\hline $\begin{array}{l}\text { Quản lý BN GMHS trong } \\
\text { phẩu thuật CKBL }\end{array}$ & $7(23,3 \%)$ & $\begin{array}{l}\text { - GMHS trên BN có bênh lý tim mạch } \\
\text { - GMHS trên BN có bệnh lý hô hấp } \\
\text { - GMHS trong PT nội soi }\end{array}$ \\
\hline Quản lý đau sau PT & $12(40,0 \%)$ & $\begin{array}{l}\text { - Các phương pháp giảm đau sau PT } \\
\text { - Giảm đau trong đẻ thường }\end{array}$ \\
\hline CSBN hồi sức sau PT & $5(16,7 \%)$ & $\begin{array}{c}\text { - CSBN sau PT nội soi, } \\
\text { - CSBN sau PT lây thai/NĐTN, sau PT chứa ngoài dạ con võ } \\
\text { - CSBN sau PT võ̃ tạng } \\
\text { - CSBN sau PT chấn thương sọ não }\end{array}$ \\
\hline Tống & $30(100 \%)$ & \\
\hline
\end{tabular}


NX: 40,0\% ĐD GMHS mong muốn đào tạo quản lý đau sau PT; $36,7 \%$ mong muốn đào tạo kiến thức về thuốc và kỹ thuật gây mê.

\section{BÀN LUÂN}

4.1. Đặc điểm chung. ĐD GMHS tập trung chủ yếu là nữ giới, chiếm $70 \%$. Tỉ lệ này cũng tương đương trong một số báo cáo về tỉ lệ $Đ D$ nữ nói chung [2], [3]. Tuổi trung bình của $\mathrm{DD}$ GMHS là $37,23 \pm 9,61$, thấp nhất 24 tuổi và cao nhất 59 tuổi, được phân bố chủ yếu trong lứa tuổi 25-39 là 66,7\%. Mặt khác số năm công tác trong chuyên ngành GMHS chiếm đa số (30\%) trong khoảng thời gian 5-9 năm (biểu đồ 3.1). Cơ cấu độ tuổi của ĐD GMHS tương tự cơ cấu của $Đ D$, hộ sinh. Kỹ thuật viên trong một số báo cáo trước đó, như của Nguyễn Việt Thắng về nguồn nhân lực ĐD, hộ sinh, KTV tại các cơ sở y tế công lập Hà tĩnh năm 2014 cho thấy mức tuối dưới 40 đạt $68,8 \%$ [4].

4.2. Trình độ chuyên môn. Kiến thức: Biểu đồ 3.1 phản ánh sự chênh lệch giữa trình độ chung và trình độ chuyên ngành ĐD GMHS, với trình độ $Đ H ~ 26,7 \%$ trong khi chuyên ngành $Đ D$ GMHS chưa ai đạt trình độ $Đ H$. Nơi đào tạo chuyên môn chiếm $83,3 \%$ là trường ĐH KTÝT Hải Dương. Năm 2014-2015 trường ĐH KTYT Hải Dương cho tốt nghiệp khóa ĐH ĐD GMHS đầu tiên; và đến năm 2020 cho tốt nghiêp khóa $Đ H$ ĐD GMHS hê vừa làm vừa học đầu tiển. Như vây 5 khóa ĐH ĐD GMHS tốt nghiệp trong thời gian qua (khoảng 200 SV) không có SV ĐD GMHS trình độ ĐH về công tác tại các TTYTH Hải Dương. Mặt khác, có tới 13,3\% ĐD GMHS mới chỉ dừng lại ở mức chuyên môn chứng chỉ phụ mê. Đây là hạn chế về kiến thức của ĐD GMHS tại TTYTH thuộc tỉnh Hải Dương.

Một số kỹ năng, thái độ nghề nghiệp: Theo bảng 3.1, ĐD GMHS tự đánh giá tốt ở các kỹ năng giao tiếp là $86,7 \%$, kỹ năng làm việc nhóm là $70 \%$, kỹ năng quản lý công việc, trang thiết bị là $53,3 \%$. Yếu ở kỹ năng thực hành chuyên môn gặp 6,7\%. Về thái độ: tuân thủ tốt các quy định khám chữa bệnh là $80 \%$; thái độ tích cực với khả năng khả năng tự học là 43,4\%; 3,3\% có thái độ yếu kém về khả năng tự hoc. Theo NC của Vũ Đình Chính (2005), đánh giá của lãnh đạo khoa về mức độ đáp ứng nhu cầu công việc của KTV GMHS tại các BV tỉnh và huyện thuộc 28 tỉnh phía bắc cho thấy: đáp ứng nhu cầu (tốt và trung bình) $96,5 \%$, mức độ yếu là 3,5\% [1].

4.3.Nhu câu đào tạo nâng cao trình độ. Từ biểu đồ 3.1 cho thây thực trạng ĐD GMHS tại TTYTH có trình độ chuyên ngành cao nhất là $\mathrm{C} \boxminus$
$(46,7 \%)$, thấp nhất là chứng chỉ (13,3\%). Mong muốn của ĐD GMHS chiếm đa số $70 \%$ là học ĐH GMHS hệ VLVH; mong muốn được đào tạo tại cơ sở trường ĐH KTYTHD là $76,7 \%$ và mong muốn thời gian học tập vào cuối tuần là $93,3 \%$ (bảng 3.2). Đa số ĐD GMHS tại các TTYTH là cựu sinh viên của trường ĐH KTYTHD $(83,3 \%)$ nên họ đều có xu hướng thích quay trở lại học tập tại trường. Thời gian học tập hiện nay phù hợp nhất với hệ VLVH là học vào những ngày cuối tuần. Mặc dù các cấp lã̉nh đạo TTYTH và quản lý bộ phận GMHS đều khuyến khích cho nhân viên đi học, song do tình trạng thiếu người, sự chuyên môn hóa sâu, sự tự chủ của cơ sở nên việc bố trí cho $Đ D$ GMHS học vào những ngày trong tuần là không khả thi.

Nội dung mong muốn được đào tạo tập chung nhiều vào lĩnh vực phụ mê phụ tê $(66,7 \%)$ và kiểm soát nhiễm khuẩn phòng mổ (50\%) (biểu đồ 3.2). Qua điều tra chúng tôi thu nhận được một số nội dung mong muốn được đào tạo cập nhật (bảng 3.3): 40\% ĐD GMHS mong muốn cập nhật Quản lý đau sau PT; 36,7\% ĐD GMHS mong muốn được cập nhật thuốc sử dụng trong gây mê như etomidate, vecuronium, naloxone, nicardipin, lipofundin, intralipid và một số kỹ thuật trong gây mê gây tê như đặt NKQ ngược dòng, xử trí đặt NKQ khó, gây mể hô hấp, gây tê đám rối thần kinh cánh tay, đám rối cổ, xử trí ngộ độc thuốc tê; 23,3\% ĐD GMHS mong muốn cập nhật thêm kiến thức về Quản lý BN GMHS trong phẫu thuật chuyên khoa bệnh lý như GMHS trên BN bệnh lý tim mạch, hô hấp, GMHS trong PT nội soi; 16,7\% ĐD GMHS mong muốn cập nhật về chăm sóc $B N$ hồi sức sau PT như sau PT nội soi, sau PT lấy thai/nhiễm độc thai nghén, chửa ngoài dạ con võ̃, sau PT vỡ tạng, sau PT chấn thương sọ não. Nội dung đào tạo Quản lý đau và Chăm sóc $B N$ hồi sức sau PT được đưa vào chương trình giáo dục ĐH ĐD GMHS và nó không có ở chương trình $\mathrm{TC}$ và $\mathrm{CÐ}[5],[6]$. Các nội dung còn lại trong các học phần Dược gây mê, Gây mê gây tê, Quản lý BN GMHS trong chuyên khoa bệnh lý đều được cập nhật so với các chương trình đào tạo TC và $C Đ$ trước đây [5], [6]. Ngoài ra, các nội dung về máy mê, máy thở, máy sốc tim, máy monitor 5,6,7 thông số cũng được cập nhật trong học phần Kỹ thuật lâm sàng so với chương trình đào tạo $\mathrm{CĐ}$ và $\mathrm{TC}$ trước đây [6].

\section{KẾT LUÂ̂N}

ĐD GMHS tại TTYTH tỉnh Hải Dương có nhu cầu lớn về đào tạo các lĩnh vực Quản lý đau sau 
PT, một số chăm sóc và kỹ thuật chuyên sâu trong gây mê, cập nhật một số thuốc mê mới, sử dụng máy mê, máy thở, máy sốc tim và công tác kiểm soát nhiếm khuẩn phòng mổ.

\section{TÀI LIẸU THAM KHẢO}

1.Vũ Đình Chính, Trân Thi Minh Tâm, Đinh Thi Diệu Hằng (2005), "Đánh giá thực trạng nguồn nhẩn lực kỹ thuât viến y tế tai các bềnh viến thuốc 28 tỉnh phía bắc", tạp chí y học thực hành ${ }_{\llcorner}$526, 7-10.

2.Nguyến Thị Thu Hà (2016), Nguyến Thị Thu Hà (2016), "Thực trạng kiên thức về kiểm soát nhiễm khuân bệnh viển của điều dưỡng viên hồi sức tích cức, bềnh viền Hữu nghi Viêtt Đức năm 2015", tạp chí y học dự phòng, Tập XXVI, số 15 (188)
3.Farid Najafi (2017), Knowledge, Attitude and Practice of Nurses Regarding Nosocomial Infections Control in Teaching Hospitals of Kermanshah University of Medical Sciences, Iran . Arch Hyg Sci, 6(4), 314- 319.

4.Nguyễn Việt Thăng (2014), Thực trạng nguồn nhân lực điều dướng, hộ sinh, kỹ thuật viên tại các cơ sở y tế công lập Hà tî̉nh năm 2014.

5.Trường đại học Kỹ thuật $\mathbf{Y}$ tế Hải Dương, Bản so sánh các trỉnh độ trung cấp - cao đẳng - đại học - của Chương trình dạy học điều dưỡng Gây mê hồi sức trường đại học Kỹ thuật $Y$ tế Hải Dương năm 2018.

6. Trường đại học Kỹ thuật $Y$ tế Hải Dương, Chương trình giáo duc đại học điều dưỡng Gây mế hồi sức trường đại học Kỹ thuật $Y$ tế Hải Dương năm 2018.

\section{KHẢO SÁT CÁC CHỈ SỐ ALBUMIN - BILIRUBIN Ở BÊNNH NHÂN XƠ GAN CÓ UNG THƯ BIỂU MÔ TẾ BÀO GAN}

\section{TÓM TẮT}

Mục tiêu: Bệnh nhân ung thư biểu mô tế bào gan (HCC) thường xuất hiên trên nền gan xớ. Nghiên cứu chúng tôi với mục tiểu áp dụng phân loại albuminbilirubin (ALBI) trong đánh giá chức năng gan. Đối tượng và phương pháp: Trong nghiên cứu chúng tôi tuyển chon được 224 bênh nhân $\mathrm{HCC}$ từ năm 2018-2019 tất cả bệnh nhân được tính toán chỉ số ALBI và phân loại Child-Pugh, phân loại Barcelona (BCLC). Kết quả: Tổng số 224 bệnh nhẩn HCC (186 nam và 38 nữ, tuổi trung bình, 28 - 90 tuổi, trung bình là 59 tuối) được đánh giá chỉ số ALBI. Bệnh nhân HCC được phân chia giai đoạn theo BCLC giai đoạn A (20.2\%), BCLC giai đoạn B $(45.7 \%)$, BCLC giai đoạn C (23.8\%) và giai đoạn D (10.3\%). Điểm ChildPugh và phân loại theo ALBI và $B C L C$ có sự tương đồng về mức độ giai đoạn. Kết luận: Nghiên cứu cho thấy rằng chỉ sổ albumin-bilirubin (ALBI) là một yếu tố có khả năng dự báo chức năng gan theo phân loại Child-pugh và BCLC ở bệnh nhân HCC.

Tư khóa: Ung thư biểu mô tế bào gan (HCC); Albumin-bilirubin (ALBI); Child-Pugh (CP)

\section{SUMMARY}

ASSESSMENT OF THE ALBUMIN-BILIRUBIN (ALBI) GRADE FOR HEPATOCELLULAR CARCINOMA PATIENTS WITH CIRRHOSIS

Objective: Hepatocellular carcinoma (HCC) in patients with cirrhosis frequently reported. We

\footnotetext{
1Trung tâm tiêu hóa gan mật bệnh viện Bạch mai 2Bệnh viện đa khoa tỉnh Hải Dương Chịu trách nhiệm chính: Nguyễn Công Long Email: nguyenconglongbvbm@gmail.com Ngày nhận bài: 11.10.2021 Ngày phản biện khoa học: 13.12.2021 Ngày duyệt bài: 21.12.2021
}

\section{Nguyễn Công Long1, Đàm Thị Phương²}

evaluated the usefulness of albumin-bilirubin(ALBI) grade as a tool for assessment of hepatic reserve function. Subjects and methods: We enrolled 224 HCC patients from 2018-2019. Child-Pugh classification and ALBI grading were calculated. Results: A total of $224 \mathrm{HCC}$ patients (186 males and 38 females, age range, $28-90$ years, average age, 59 years) were valuated ALBI. According to BCLC classification, BCLC stage A $(20.2 \%)$, BCLC stage $B(45.7 \%)$, and BCLC stage $C(23.8 \%)$ and stages $D(10.3 \%)$. Child-Pugh clasifications and ALBIbased BCLC systems were highly concordant. Conclusions: the albumin-bilirubin (ALBI) grade, as a prognosticator has demontrated that was correlated with Child-pugh clasification and BCLC stages in HCC patients.

Keywords: Hepatocellular carcinoma (HCC); Albumin-bilirubin (ALBI); Child-Pugh (CP)

\section{I. ĐẶT VẤN ĐỀ}

Hầu hết bệnh nhân ung thư biểu mô tế bào gan có liên quan đến bệnh gan mạn tính, thường trên nền xơ gan phát triển thành HCC. Tỉ lệ sống còn của bệnh nhân HCC phụ thuộc giai đoạn khối u và chức năng gan[1]. Ngoài ra năm 2015 phân điểm ALBI được đề xuất để đánh giá chức năng gan của bệnh nhân. Chỉ số này gồm hai yếu tố khách quan là Albumin và bilirubin toàn phần[2]. Một số điều tra đã xác nhận rằng điểm ALBI tốt hởn điểm Child-Pugh khi dự báo chức năng gan của bệnh nhân cũng như tiên lượng của bệnh nhân sau khi cắt bỏ gan và điều trị bằng phóng xạ hay đốt sóng cao tần[3]. Ở Việt Nam nền kinh tế còn nhiều khó khăn, việc đánh giá chức năng gan cũng như tiên lượng bệnh nhân ung thư biểu mô tế bào gan dựa vào chỉ số ALBI là phương pháp mới khách quan, dễ triển 